\title{
Comparação crítica entre demandas e técnicas de levantamento: o papel da memória em projetos de conservaçáo e restauração arquitetônica*
}

Critical comparison between survey demands and techniques: the
role of memory on architectural conservation and restoration projects

Pedro Murilo Gonçalves de Freitas

Arquiteto (FAU-USP), especialista em Teoria e Prática da Preservação e do Restauro de Bens Arquitetônicos e Urbanísticos e mestrando do Programa de Pós-graduação em Arquitetura, Tecnologia e Cidade (FEC-Unicamp) pmugf.arq@gmail.com

\section{Resumo:}

A restauração contemporânea tem afirmado o reconhecimento da matéria dos edifícios como preceito fundamental. Contudo, do ponto de vista operativo, esta tarefa é atividade complexa, ligada aos referenciais do intérprete. Este artigo busca apresentar estudo de caso conduzido no levantamento da capela Panagia Vlaherna, em Zakynthos, Grécia, durante workshop internacional multidisciplinar de conservação arquitetônica. Comparam-se diferentes técnicas de levantamento e representação disponíveis para discutir demandas e a aplicabilidade destes instrumentos a profissionais interessados na preservação dos edifícios.

Palavras-chave: Reconhecimento da arquitetura existente; Projeto de conservação; Métodos de levantamento

\section{Abstract:}

The contemporary restoration has been affirmative about the acknowledgement of building fabric as a fundamental precept. However, from the operational point of view, this task is a complex activity, based on interpreter's references. This article aims to present a case study conducted on the survey of Panagia Vlaherna Chapel, at Zakynthos, Greece, during an international and multidisciplinary workshop of architectural conservation. It compares different available survey and representation techniques in order to discuss demands and applicability of these instruments to professionals interested on buildings preservation.

Keywords: Acknowledgement of existing architecture; Conservation project; Survey methods

* Trabalho apresentado no GT Memória e Patrimônio: Entre Ciência e Técnica 
1 - Este trabalho é parte de pesquisa de mestrado em andamento financiada pela Fundação de Amparo à Pesquisa do Estado de São Paulo (FAPESP) denominada "O Desenho e o Reconhecimento do Objeto Histórico: os princípios metodológicos do projeto de restauro arquitetônico", desenvolvida sob orientação da Prof. Dra. Regina Andrade Tirello no Grupo de Conservação e Restauro da Arquitetura e Sítios Históricos (GCOR-Arquitetura) e no âmbito do Programa de Pós-Graduação em Arquitetura, Tecnologia e Cidade da Faculdade de Engenharia Civil, Arquitetura e Urbanismo da Universidade Estadual de Campinas (FEC-Unicamp).

2 - "A restauração constitui o momento metodológico do reconhecimento da obra de arte, na sua consistência física e na sua dúplice polaridade estética e histórica, com vistas à transmissão para o futuro." (BRANDI, 2005:30).

3 - "Restaura-se somente a matéria da obra de arte." (BRANDI, 2005:31).

4 - Verificar, em especial, os artigos 3 e 9 da Carta de Veneza de 1964, adotada em âmbito internacional. Cf. INTERNATIONAL COUNCIL ON MONUMENTS AND SITES, 1964:2.

5 - "Il riconoscere implica l'azione della memoria che rinvia ad un già conosciuto, ma anche la capacità critica di distinguere-identificando, che è una presenza attiva, perché comporta appunto azione di orientamento e di separazione."

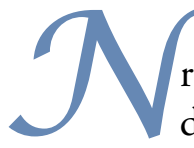

a fundamentação[1] de seu principal axioma[2] sobre a restauraçáo, publicado pela primeira vez nos anos 1960, Cesare Brandi (2005: 25-30) buscou refletir sobre os critérios de eleição que selecionam os objetos artísticos de sua esfera comum, o conjunto de bens do "produto da atividade humana”. A Restauração, na definição brandiana, opera como ato crítico que busca restituir eficiência a estes produtos. Em seus procedimentos, privilegia como atividade o reconhecimento da substância física da obra de arte[3], representante e evocativa dos valores intrínsecos que devem ser preservados e transmitidos sem ambiguidades às geraçóes futuras.

Em ressonância a essas diretrizes preconizadas até hoje, a teoria da Restauração contemporânea tem afirmado o reconhecimento da matéria dos edifícios como preceito fundamental para o desenvolvimento do projeto de intervenção. Este reconhecimento é base tanto do ato crítico de restauro em si do bem arquitetônico, como no âmbito dos procedimentos de conservação da matéria arquitetônica aos pósteros. Porque transliterados estes princípios em importantes cartas e recomendaçóes internacionais, que consolidaram a existência do campo disciplinar autônomo, este procedimento deve refletir a base de qualquer projeto em nível preservacionista[4]. Contudo, do ponto de vista operativo, este reconhecimento é atividade complexa, que envolve capacidades cognitivas específicas, ligadas aos referenciais de quem interpreta a arquitetura existente. Da mesma forma que um objeto pode conter em si e ser atribuído de valores diferentes, muitas vezes sobrepostos, um arquiteto que se ocupa em "recuperá-lo em sua eficiência” será ditado, ainda que inconscientemente, por valores intrínsecos à sua formação, sendo o mesmo válido para historiadores, sociólogos, antropólogos, engenheiros, entre outros. Por este sentido, toda a restauração e/ou conservação reclama, e deve ser, conscientemente multidisciplinar, de forma a atingir essa possível amplitude de valores do objeto - entre históricos e artísticos, mas também arquitetônicos, arqueológicos, paisagísticos, entre outros -, em todos os campos do saber. Nas palavras de Paolo Torsello (1988: 59, tradução nossa),

reconhecer implica a ação da memória que se refere a algo já conhecido, mas também à capacidade crítica de distinguir-identificando, uma presença ativa, porque comporta exatamente açóes de orientação e separação"[5].

Assim, apesar da existência dos enunciados brandianos, do ponto de vista prático, um mesmo edifício pode ser lido de diferentes maneiras, levando também à possibilidades de projeto independentes (ou contraditórias), que variam, desde o estudo da matéria do ponto de vista estritamente arqueológico à sugestóes arquitetônicas de recuperação ou transformaçáo espacial e funcional. Reconhecer a matéria arquitetônica, porque atividade subjetiva, refere-se às necessidades cognitivas da memória do intérprete, que resulta, enquanto processo, na seleção histórica dos edifícios.

Por analogia à dialética do binômio documento/monumento explicada por Jacques Le Goff (1990: 545), ocupar-se da preservação dos edifícios é uma ativida- 
de que se orienta por valores e saberes em relação ao objeto que se dispóe à seleção (ou não), num debate que engloba o arcabouço teórico e o conhecimento técnico de diferentes profissionais que atuam na preservação dos bens culturais[6].

Portanto, diante da ampliaçáo do conceito de patrimônio nos últimos anos, que torna esta situaçáo, pela natureza prática, ainda mais inevitável - ou seja, é impossível tudo preservar -, cabe a questão no plano dos instrumentos: de que forma, com que métodos e técnicas, deve ser imprescindível ao "ato crítico", emanado pela teoria, torná-lo o mais amplo possível, que considere, ao menos em sua maior parte, todo o universo de saberes que potencialmente estão presentes de forma difusa nos bens culturais? Será que isso é possível?

\section{O DESENHO DE LEVANTAMENTO: LEITURAS E DEMANDAS}

No Brasil, existe uma tendência a associar o registro da arquitetura à atividade do arquiteto. Com sua prática, seus métodos e recursos, o levantamento ato no projeto de registrar a arquitetura - é, normalmente, uma representação do espaço da intervenção que pretende executar. Neste momento, pela sua observação fixa na composição do espaço, ou pela busca métrica do conjunto, em geral, detém-se em elementos secundários de forma subjetiva. Uma tomada elétrica ou a esquadria de uma porta, por exemplo, embora sejam características essenciais para o planejamento de um layout, que fogem e interferem no espaço delimitado pelas paredes, são corriqueiramente representados sob forma de convençôes preestabelecidas, em que sua posição real no espaço, não corresponde exatamente à sua localização. Estes elementos, normalmente, são classificados de forma tipológica e temática, em um detalhamento posterior.

Em oposição, um arqueólogo, por conceber toda a resultante material de um sítio ou estrutura como fator condicionante de sua pesquisa, detém-se de forma exaustiva e cuidadosa em cada unidade física que pretende documentar, na arquitetura ou no terreno. Na concepção de um arqueólogo, pela resultante de sua formação, a representação do espaço está totalmente condicionada pela fidelidade material do objeto que representa. A posição de um osso numa câmara funerária, ou a composição estratigráfica de uma pintura parietal, ou das camadas do solo ou das técnicas construtivas aplicadas, pode levá-lo à conclusôes paradigmáticas importantes, ainda que nem sempre condicionadas pela percepção espacial do conjunto que possa orientá-lo em suas conjecturas.

Em projetos de conservação e/ou restauração, este conflito é evidente. $\mathrm{Na}$ medida em que componentes espaciais e associaçóes materiais se revelam paulatinamente processos de evidência histórica e/ou de sistemas e técnicas de construção tradicionais alteradas ou intactas, a percepção destes elementos depende de uma complexa operação interativa entre variados campos do saber. Mesmo que a restauração, para ser efetiva, requeira das instâncias da função e do uso como garantias de preservaçáo do edifício - que evidentemente relacionam o projeto a uma base arquitetônica -, a representação deficiente de um objeto pode náo suscitar a evidência de processos de degradação material e levar a um reconhecimento global inadequado do bem cultural.

Destaca Daniela Manacorda (2009: 113-114, tradução nossa), portanto, resumindo o seguinte dilema em âmbito profissional:

Entre arqueólogos e arquitetos - que trabalham num canteiro de escavação urbana e de restauração de edifí-
6 - Aspectos similares podem ser verificados nas políticas de inventário e tombamento de bens culturais e indicam a responsabilidade do papel do profissional da preservação enquanto mediadores simbólicos de um importante processo de seleção histórica. Cf. FONSECA, 2009:22. 
7 - "Tra archeologi e architetti-che operano nei cantieri di scavo urbano e di restauro dell'edilizia storica - è in corso da tempo un dibattito, che trae spunto da una riconosciuta distinzione di ruoli, ma esprime la convinzione che occorra ristabilire una cultura comune nell'approccio agli aspetti materiali degli insediamenti urbani. C'è un problema reale di formazione archeologica degli architetti e un problema di educazione degli archeologi alla cultura della progettazione."
8 - "Non sarà superfluo rammentare come proprio I'analisi diretta, eseguita a vista e con il solo strumento del disegno, possa dare risultati imprevedibili e di grande soddisfazione; essa sarà tanto più efficace quanto più l'operatore risulterà ben addestrato $e$ capace di padroneggiare $i$ metodi della rappresentazione, insieme con la storia dell'architettura, le tecniche diagnostiche, la teoria e la pratica del restauro." (Grifos meus). cios históricos - está em curso há tempos um debate que traz em princípio uma reconhecida distinção de papéis, mas exprime a convicção da necessidade de restabelecer uma cultura comum na abordagem dos aspectos materiais dos sítios urbanos. É um problema real de formação arqueológica dos arquitetos e um problema de educação dos arqueólogos à cultura da projetação[7].

Entende-se que, diante dessa reconhecida necessidade, em um projeto de restauração ou conservação, uma "cultura comum", ao menos inicialmente, se faz pelo desenho arquitetônico, que se coloca metodologicamente como princípio de estudo preventivo essencial (SANPAOLESI, 1980: 61) e é requerido de forma ampla por profissionais de diversas formaçóes enquanto equilíbrio de linguagens (FREITAS; TIRELLO, 2010: 6). O levantamento, atividade que precede qualquer ato sobre a arquitetura, é procedimento basilar não apenas em âmbito instrumental, mas é aquele elemento essencial no processo de projeto de conservação e/ou de restauração que subsiste à sua fidúcia técnica, verificação e compreensão em uma síntese crítica, em diversos aspectos que confluem de modo preciso nos bens que se registra (ECKSTEIN, 1999: 11). Conforme aponta Giovanni Carbonara (1989: 85, tradução nossa, grifos nossos),

Não será supérfluo recordar como a própria análise direta, executada à vista e com um só instrumento de desenho, pode dar resultados imprevisíveis e de grande satisfaçáo; essa será tanto mais eficaz quanto mais o operador for bem adestrado e capaz de padronizar os métodos de representação, em conjunto com a história da arquitetura, as técnicas diagnósticas, a teoria e a prática do restauro[8].

Assim, em acordo com a disciplina da Restauração contemporânea, o ato de levantar, cadastrar, medir reafirma-se como prática imprescindível ao registro dos valores históricos plenos de uma dada obra, que, ao se tornarem documentos - derivaçáo do latim docere, que significa ensinar, demonstrar - em diversos suportes descritivos como croquis, elevaçóes, plantas e perspectivas, em escalas adequadas e coerentes à representação exata do objeto de estudo, permitem a difusão do conteúdo histórico e estético dos bens, numa dimensão tão mais abrangente quanto possível e que interessa à critica arquitetônica, à projetação atual e à pesquisa em diversas áreas do conhecimento correlatas.

A essas possibilidades soma-se, ainda, o desenvolvimento do campo da representação gráfica, que hoje conta com o auxilio de diversos meios computacionais e vem sugerindo novos suportes de gestão e manipulação da informação à área da preservação. Estes podem hoje

(...) constituir-se em uma instância qualificada de análise dos objetos do passado, desde que adequadamente balizados por documentos escritos e formas que os constituem e caracterizam. Sua concepção legitima-se quando apoiada em pesquisas multidisciplinares e em avaliaçóes críticas da qualidade dos conteúdos históricos 
expressos nos e pelos bens culturais que se quer representar (TIRELLO, 2008: 2).

Este artigo busca colocar em discussão um estudo de caso conduzido em workshop internacional durante as atividades de conservação de uma capela de meados do século XIX, em Zakynthos, Grécia. Com base nesses princípios, visou-se comparar diferentes técnicas de levantamento e representação disponíveis a projetos de conservaçáo para discutir a aplicabilidade destes instrumentos em uma visão mais ampla de profissionais interessados na preservação dos edifícios.

\section{ESTUDO DE CASO}

O workshop, denominado Project Romiri[9], teve o objetivo de reunir uma equipe de jovens especialistas, entre arquitetos, historiadores da arte, conservadores e arqueólogos, para discussáo de conceitos teóricos e metodológicos da conservaçáo por meio de estudos de casos aplicados em bens culturais gregos. A importância do evento - centrado na capela familiar denominada Panagia Vlaherna, próxima à localidade de Romiri, na cidade de Zakynthos, situada na ilha de Zante, Grécia [Figura 1] - residiu nas dimensóes reduzidas da edificação, o que permitiu a organização de seminários temáticos em cinco semanas - contexto, levantamento, diagnóstico, intervenção e disseminação -, em que foram trabalhadas todas as etapas necessárias para a conservação do bem, garantia de uma visão completa dos procedimentos de projeto e intervenção.

A metodologia de trabalho do evento relacionava estudos que implicavam

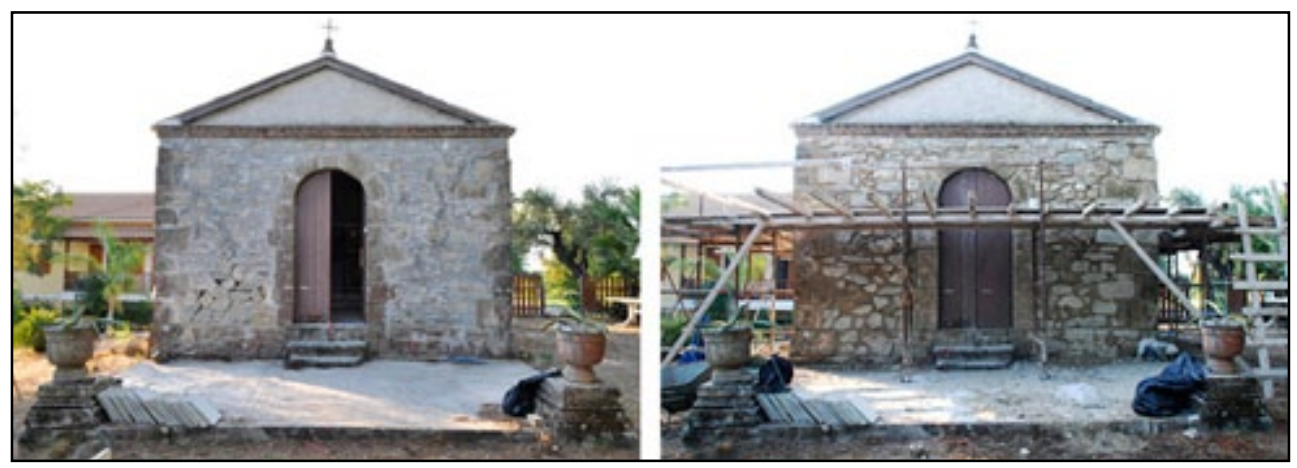

Figura 1 - A capela familiar Panagia Vlaherna, antes e durante os trabalhos do workshop. Fotos do autor, 2011.

um gradual reconhecimento da matéria construída, de atividades antecedidas por palestras convidadas que, em seguida, direcionavam sua aplicação à solução de problemas relacionados ao objeto de trabalho. Esta combinação, por assim dizer "focada" no edifício, permitiu o enfrentamento direto de posturas teóricas face a procedimentos práticos, deixando evidente, a partir de uma associação que emana exclusivamente do canteiro, a necessária verificaçáo de determinados construtos teóricos em casos específicos, nem sempre aplicáveis enquanto princípios, para ampliar o leque de abordagens existentes e possíveis sobre o objeto histórico entre esses diferentes profissionais.

Como procuramos discutir desde o início, os aspectos abordados neste artigo são referentes à segunda semana de atividades, relacionada à prática de levantamentos métricos e coleta de dados da arquitetura existente, objeto também de nosso interesse na pesquisa de mestrado em andamento[10]. Para esse fim, foram utilizados três dife-
9 - Evento organizado pela Diadrasis Interdisciplinary Research on Archaeological \& Architectural Conservation, com apoio da Universidade de York, Reino Unido, do International Centre for the Study of the Preservation and Restoration of Cultural Property (ICCROM, Itália) e do Ministério da Cultura da Grécia, com chamada internacional de inscrição a arquitetos, engenheiros civis, arqueólogos, historiadores e conservadores. Cf. DIADRASIS INTERDISCIPLINARY RESEARCH ON ARCHAEOLOGICAL \& ARCHITECTURAL CONSERVATION, 2011.

10 - Por este motivo, a participação neste workshop teve o auxílio da Fundação de Amparo à Pesquisa do Estado de São Paulo (Fapesp) e o Fundo de Apoio ao Ensino, Pesquisa e Extensão da Universidade Estadual de Campinas (Faepex-Unicamp), instituições às quais agradecemos o apoio concedido para participação no evento. 


\section{Artigos \& Ensaios}

rentes métodos diretos ou indiretos, comumente aplicados a projetos de conservação e/ou restauração -, desenho à mão, em imagem retificada e escaneamento tridimensional - para discuti-los em sua aplicabilidade, vantagens e limites operativos.

\section{DESENHO A MÃo}

O desenho à mão, embora aparentemente trivial e tradicionalmente relacionado à dimensão artística, é atividade que requer especialização e controle científico para os fins a que se destina no projeto de conservação. Ao representar a matéria para fins documentais, é uma atividade que passa, necessariamente, pelo crivo e competência artística do desenhista, seu intérprete, mas que requer planejamento e uma condução racional relativa ao objeto para que assuma o valor científico de que se solicita (DOCCI; MAESTRI, 2009: 67).

Sob uma retícula previamente estabelecida nas fachadas do edifício, com fios de prumo a distâncias equivalentes, estabeleceram-se os planos e pontos referenciais de suporte ao processo de documentação da arquitetura, sejam horizontais, relacionados à elaboração das plantas do edifício, sejam verticais, em relação às elevaçóes exteriores e interiores. Os instrumentos utilizados para a elaboração do registro arquitetônico foram simples e tradicionais: uma prancha rígida suportou um papel vegetal, selecionada por conter distorções métricas por dilatação; nele, registrou-se com uma lapiseira grafite profissional a informação primária da matéria arquitetônica obtida por triangulação (principalmente das plantas) ou retangulação (elevaçóes), em relação a estes pontos e planos no desenho. A partir do momento em que determinadas quadrículas tinham a informaçáo finalizada, referindo-se ao posicionamento de pontos marcantes à evidência de cortes e formatos característicos das pedras aparentes, o desenho era completado por proporção visual direta [Figura 2].

As vantagens do desenho à mão estão, essencialmente, relacionadas à sua

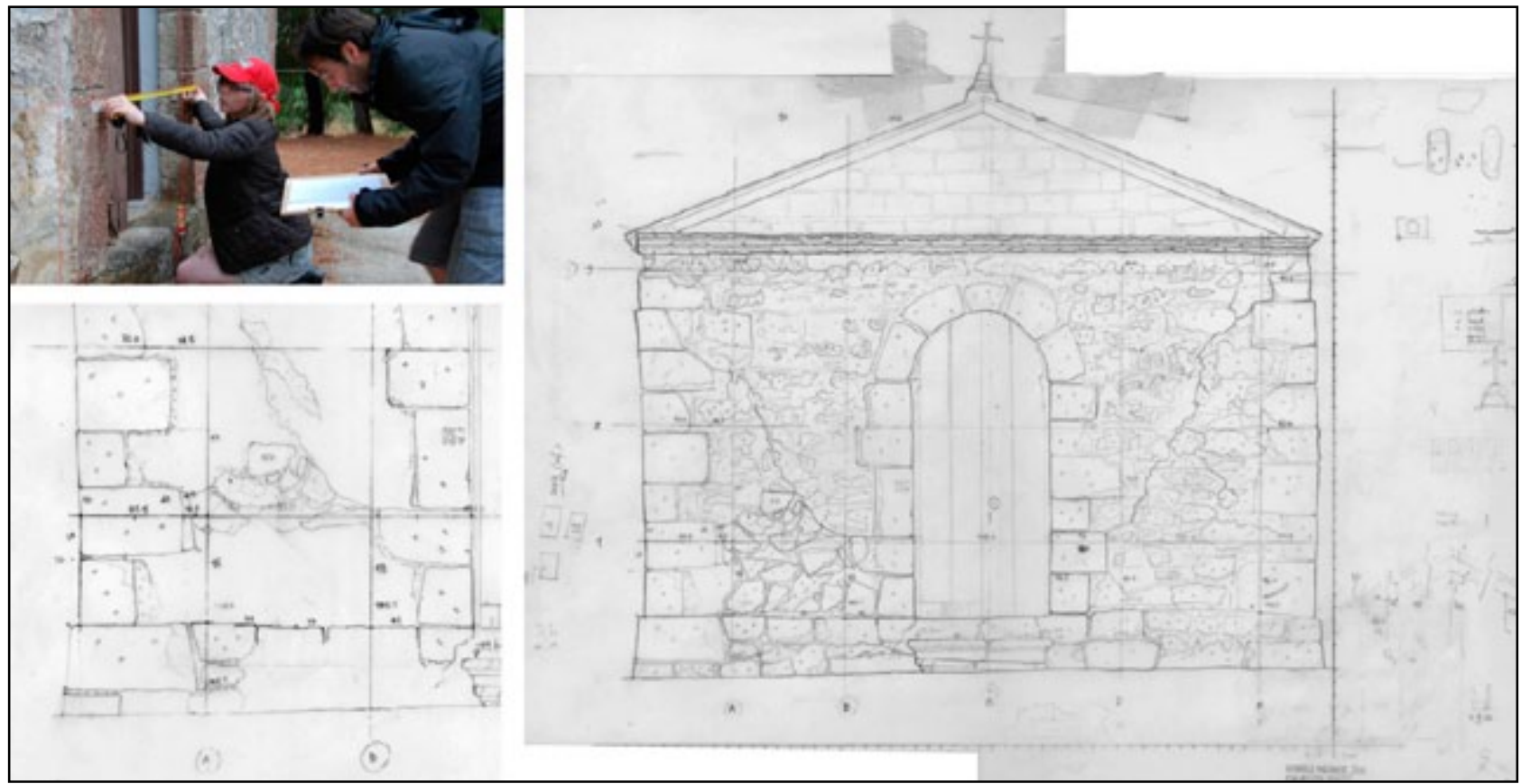

Figura 2 - Processo de levantamento métrico direto com registro à mão livre. Foto: Lucía Gómez-Robles; Desenhos do autor. Acervo Diadrasis, 2011. 
fenomenologia cognitiva, facilidade e flexibilidade de produção e baixo custo material. $\mathrm{O}$ contato direto com o objeto permitiu rever medidas de controle inconsistentes, confrontar informaçóes intrincadas e, essencialmente, conhecer e documentar a fundo a matéria arquitetônica, exaurida ao máximo possível. Por este motivo, do ponto de vista da conservação, também porque tradicionalmente associado (e em congruência) à premissas arqueológicas, o ato de desenhar estabelecia no intérprete da matéria construída uma essencial conexão com o objeto, tornando-o tangível em muitos aspectos, desde formais como também relativos a processos de compreensão histórico-crítica (CARBONARA, 1989: 92). Desse modo, é uma atividade que, pela natureza, remove a subjetividade na representação documental do edifício construído e permite análises mais profundas e coerentes.

No entanto, o tempo - ao fim considerado reduzido para a atividade no workshop - refletiu as limitaçóes do uso prático do desenho à mão, cujo trabalho em uma semana resultou em poucos produtos. A eficiência de uma morosa atividade exige, em contrapartida ao baixo custo material, um alto custo humano. Como experimento, todavia, implicou um conhecimento do objeto fundamental para as atividades posteriores, previstas na preservação do edifício.

\section{DESENHO COM IMAGEM RETIFICADA}

A imagem retificada ou ortofoto tem ampliado seus usos a levantamentos métricos-arquitetônicos pela difusão de novos programas de computador que possibilitam a rápida edição fotográfica, antes associada a instrumentos complexos[11]. Seu uso tem permeado o campo da preservação por garantir rápida documentação técnica dos bens e, como procedimento facilitador, permitir estabelecer uma referência gráfica com uma grande quantidade de informaçóes não documentadas à primeira vista, ou de difícil interpretação e representação, como cores e texturas. A fotografia, nesse sentido, retificada em sua grandeza topológica (CATTANI, FIORINI, 2004: 317), complementa e permite confluir desde estudos de natureza construtiva (entre patologias e interaçôes materiais) a cadastros somente morfológicos sobre o objeto arquitetônico.

$\mathrm{Na}$ capela, com base nos planos de referência já criados, procedeu-se à tomada de fotografias das fachadas, buscando-se a maior ocupação possível do objeto no quadro da imagem, de modo a evitar perdas de resolução. Em desenho de apoio, anotou-se a posiçáo dos alvos fixos a determinados elementos arquitetônicos para estabelecer o posicionamento em verdadeira grandeza desses pontos em um sistema de coordenadas CAD. A orientação da tomada das fotografias, para máxima eficiência exigida pelo projeto, teve, ainda, base referencial cromática e compreendeu discussóes sobre a resolução esperada para impressão escalada, sobretudo como produto final útil ao workshop em andamento. Após a inserção dos dados para calibragem da câmera, a retificação foi, assim, conduzida por um processo de verificaçáo do erro entre os pontos selecionados, devendo que fossem ao máximo coplanares e distribuídos pelo objeto, caso contrário este erro seria calculado e oferecido ao operador para refazer o processo, oferecer mais pontos de suporte ou aceitar o erro gerado pela operação. A partir da imagem retificada em um plano ortogonal, foi possível elaborar o desenho vetorial da edificação com o auxílio de programas CAD [Figura 3].

Do ponto de vista operacional, as vantagens da retificação fotográfica são
11 - Os programas disponíveis para a retificação de imagens estão em constante mutação, característica do mercado e da pesquisa recente em tecnologia da informação; comuns no campo da geomática, contudo, pode-se dizer que os atuais programas de baixo custo se baseiam essencialmente em procedimentos tradicionais de fotogrametria, executados por algoritmos de correção geométrica da informação obtida em um mapa de pixels (a imagem). Atuam na correção das distorções da tomada fotográfica seja pela lente da câmera, seja pela perspectiva - a sistemas referenciados por pontos pré-estabelecidos, podendo ser em somente um plano (ortofoto), como em comandos simples de edição (crop: perspective) oferecidos pelo Adobe Photoshop ou o plugin Photoplan para AutoCAD, ou em vários planos simultaneamente (estereoscopia), como o PhotoModeler, entre outros.

Entende-se por consumo de recursos materiais, não somente o gasto de material no processo de levantamento, mas também o consumo indireto relacionado à manutenção do equipamento de campo e/ou aquisição de programas de computador. 


\section{Artigos \& Ensaios}

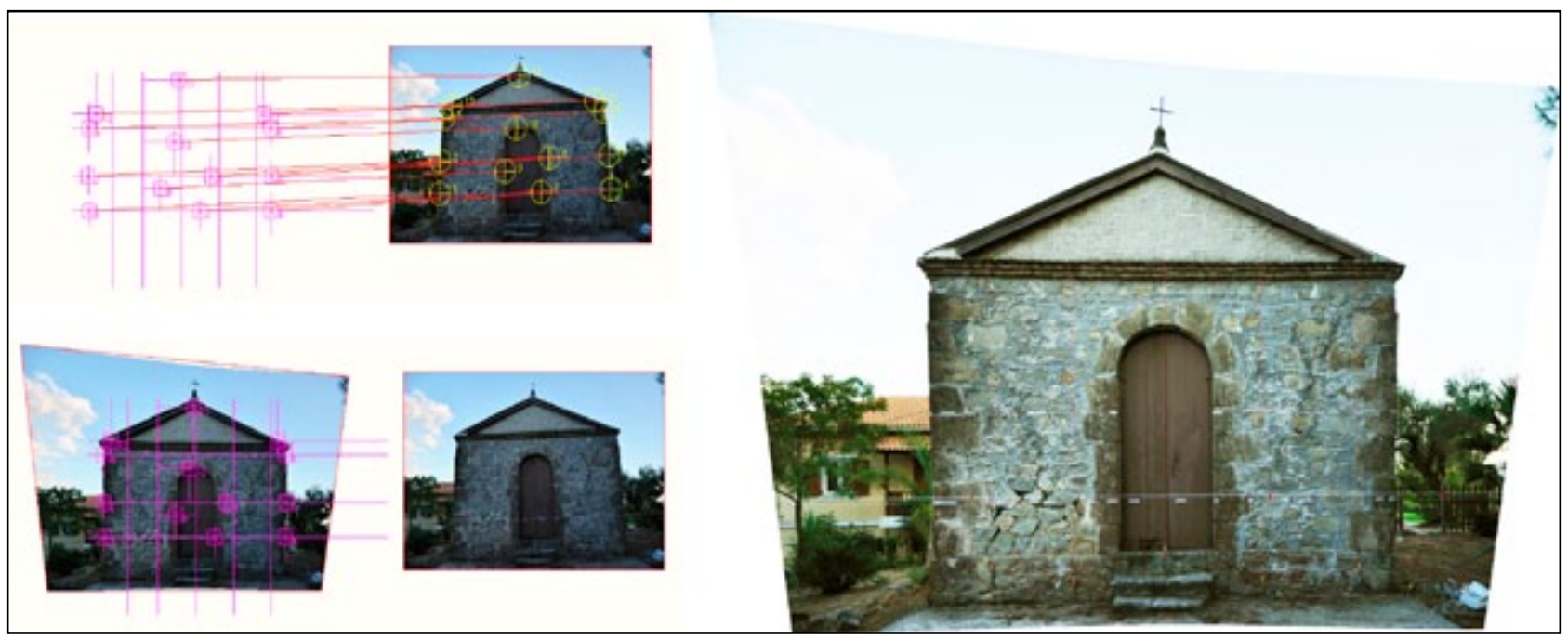

Figura 3 - Processo de retificação fotográfica com uso de sistemas computacionais simples (no caso, plugin PhotoPlan para AutoCAD). Fotos e desenhos do autor. Acervo Diadrasis, 2011.

muitas e isso explica sua popularidade atual, especialmente na produção de mosaicos ortofotográficos, que remetem às tradicionais documentaçôes fotográficas por montagem panorâmica em projetos de conservação. Além da redução de tempo na documentaçáo do objeto, podem ser aplicadas em casos de emergência ou de tempo reduzido. Ainda, quando combinada ao desenho à máo in situ, realizado em adequada representação escalar, tornam-se fontes complementares de suporte ao projeto de conservação, e assumem, pela natureza do registro fotográfico, um importante significado expressivo (SANPAOLESI, 1980: 66).

A transferência do dado fotográfico é, contudo, geralmente realizada numa locação remota, independente do objeto. Desnecessário dizer que mediçôes diretas prévias são necessárias, sendo que e a técnica se limita a produtos verticais (fachadas) e planos lisos, mas que ainda pode ser utilizada em objetos complexos, desde que seja realizado um criterioso planejamento e controle de erros. Assim, embora seja registrada uma imagem em alta resolução, a informação oferecida ainda precisa ser interpretada de forma eficiente para que os dados relevantes sejam dela extraídos, já que o processo de retificação bidimensional não corrige automaticamente distorçôes de materiais não coplanares à referência preestabelecida. Tais distorçôes demonstram, muitas vezes quando acontecem, a pouca relaçâo deste método de documentação entre a matéria da arquitetura e o operador.

\section{DESENHO COM ESCANEAMENTO A LASER}

Da mesma forma que as ortofotos, o escaneamento a laser (ou digitalização 3D) tem sido uma alternativa compatível a projetos de conservação e/ou restauração. Por produzirem imagens em alta resoluçáo e quantidade de dados combinados em uma "nuvem de pontos" tridimensional, relacionam o objeto à sua representaçáo de modo intrínseco, sendo que o produto obtido por esse método compóe um modelo reduzido do objeto, passível de inúmeras aplicaçôes analíticas e/ou documentais.

O escaneamento a laser da capela realizado no workshop foi, simultaneamente, aplicado aos dois métodos anteriores para comparaçáo de sua efetividade enquanto parte do projeto em andamento. Para criação do modelo tridimensional, foi utilizado escâner de médio alcance em seis principais pontos ao redor do objeto e cinco pontos no seu interior, determinando-se, previamente, a divergência do feixe de lasers de acordo 
com a resolução solicitada e o ângulo de abertura vertical e horizontal do campo visual (field-of-view). Após o registro automatizado, gerou-se a nuvem de pontos que foi trabalhada de forma a eliminar ruídos ambientais indesejados, como vegetação aparente, movimentação e sombras por projeção em programas de manipulação específicos. Em seguida, de posse do modelo, foram realizadas imagens em épura simples e cortes horizontais a diversas alturas, para continuidade dos trabalhos do evento [Figura 4].

Por utilizar ferramentas de alta precisão, este método tem entre suas prin-

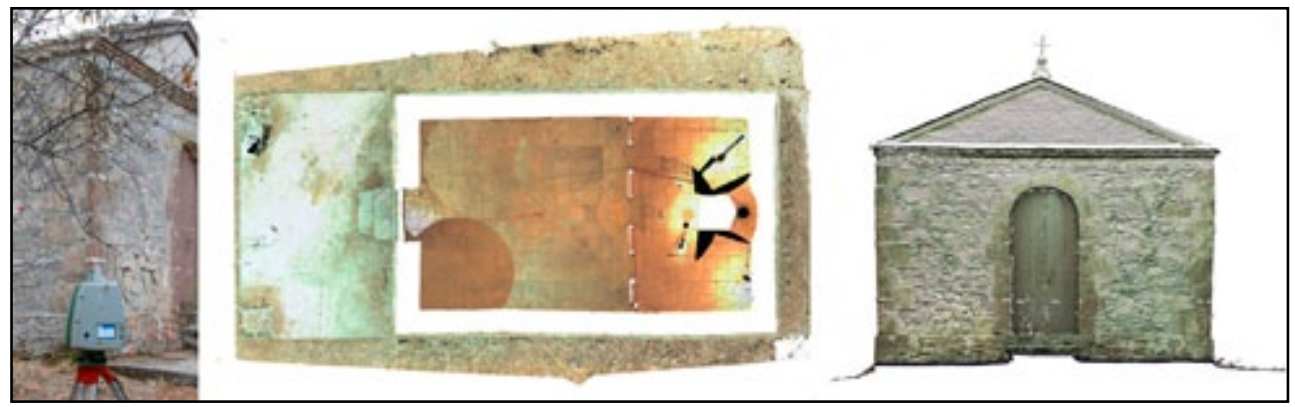

Figura 4 - Escaneamento tridimensional a laser em campo e produtos oferecidos (planta a $1 \mathrm{~m}$ do solo e fachada) após edição da nuvem de pontos obtida (no caso, estação Leica ScanStation C5 e edição realizada em programas da linha Leica, CloudWorx e Cyclone). Foto: Lucía Gómez-Robles; Desenhos: Katie Simon. Acervo Diadrasis, 2011.

cipais vantagens a acuidade do dado material, obtida em pouco tempo. No planejamento geral do levantamento, permite que sejam dimensionadas de forma precisa os recursos utilizados para se obter os produtos solicitados, que podem ser conseguidos, também, em casos emergenciais e serem realizadas as operaçôes de coleta quantas vezes forem necessárias. É, ainda, uma tecnologia cuja total aplicação em projetos de conservação e restauração ainda está por ser testada completamente.

Por essa razão, aí residem suas principais desvantagens, além do alto custo de aquisição e manutenção, tanto do equipamento quanto dos programas de computador utilizados. Como processo que utiliza um feixe de lasers rebatidos sobre objetos opacos dentro do campo de visão determinado, o equipamento registra a completa condição da cena, gerando uma enorme quantidade de informação, por vezes irrelevantes. Embora a aquisição do dado material seja veloz, o processamento dessa informação é bastante lento e dependente da interação do operador, gerando produtos que são, no âmbito da conservação, por vezes facilmente obtidos com outros métodos alternativos, mais simples e menos custosos, além de colocar dúvidas sobre a acessibilidade e preservação do dado digital após um longo período de tempo.

\section{CONSIDERAÇótes Finais}

$\mathrm{Na}$ aplicação dos três processos, realizada individualmente durante o workshop Project Romiri, um comparativo dos métodos de levantamento foi realizado [Tabela 1].

Diante da busca por essas "vantagens" e "desvantagens" entre a equipe multidisciplinar, ficou evidente que há uma necessidade intrínseca nesses métodos - aplicáveis em etapas distintas em cada um deles - de caracterizar (pela noção de distorção ou controle do erro) a interação direta do usuário com o instrumento utilizado para extrair do objeto levantado uma efetiva e relevante informação, independente do processo. Desse modo, torna-se óbvio que os 
processos automatizados, ainda que qualificados recentemente pela capacidade de economizar tempo nos procedimentos e possibilitar reproduçóes digitais do documento, ainda não podem substituir a interação do usuário do instrumento com a matéria da arquitetura, substância inegável do bem cultural.

Nesse sentido, e recuperando nossa questão inicial, embora a verificação das téc-

\begin{tabular}{|c|c|c|c|}
\hline & Desenho a mão & $\begin{array}{l}\text { Desenho em } \\
\text { imagem retificada }\end{array}$ & $\begin{array}{l}\text { Desenho com } \\
\text { escaneamento } \\
\text { a laser }\end{array}$ \\
\hline Natureza do registro & Arqueológica & Arquitetônica & $\begin{array}{l}\text { Arqueológica e/ou } \\
\text { Arquitetônica }\end{array}$ \\
\hline Automação & Inexistente & Baixa & Alta \\
\hline Acuidade & Subjetiva & Subjetiva & Objetiva \\
\hline Controle de erros & Focada no objeto & Em local remoto & Em local remoto \\
\hline $\begin{array}{r}\text { Consumo de recursos humanos } \\
\text { na aquisição de dados } \\
\text { no processamento de dados }\end{array}$ & $\begin{array}{l}\text { Alto } \\
\text { Alto }\end{array}$ & $\begin{array}{l}\text { Médio } \\
\text { Alto }\end{array}$ & $\begin{array}{l}\text { Baixo } \\
\text { Alto }\end{array}$ \\
\hline $\begin{array}{l}\text { Consumo de recursos materiais } \\
\text { Na aquisição de dados } \\
\text { No processamento de dados }\end{array}$ & $\begin{array}{l}\text { Baixo } \\
\text { Baixo }\end{array}$ & $\begin{array}{l}\text { Médio } \\
\text { Alto }\end{array}$ & $\begin{array}{l}\text { Alto } \\
\text { Alto }\end{array}$ \\
\hline Reprodutibilidade do documento & Limitada & Alta & Alta \\
\hline
\end{tabular}

Tabela 1 - Quadro comparativo.

nicas disponíveis, a consciência do contexto do levantamento enquanto processo cognitivo determinou que, ao final dos testes elaborados, fosse revisto o protocolo de análise em relação ao tipo de reconhecimento da matéria solicitado. Concluiu-se que o maior ganho desse estudo de caso não foi, portanto, identificar as técnicas, mas sim comparar, através do referencial teórico e profissional de cada um, as demandas esperadas em relação aos resultados efetivamente obtidos. A equipe de trabalho, suas especialidades, formas de controle crítico e tipos de solicitaçóes gráficas foram reagrupadas na seguinte tabela [Tabela 2]:

Chegou-se à conclusão que, enquanto historiadores da arte dependem de uma

\begin{tabular}{|c|c|c|c|c|}
\hline & Historiadores da Arte & Arquitetos & Conservadores & Arqueólogos \\
\hline Participantes & 1 & 4 & 2 & 1 \\
\hline Especialidades & Catalogação de acervo & $\begin{array}{c}\text { Conservação e } \\
\text { Restauro; } \\
\text { Planejamento } \\
\text { Urbano; } \\
\text { Análise Estrutural }\end{array}$ & Materiais Pétreos & $\begin{array}{c}\text { Arqueologia da } \\
\text { Arquitetura }\end{array}$ \\
\hline Controle Crítico & Fontes indiretas & Fontes diretas e & $\begin{array}{c}\text { Fontes diretas e } \\
\text { indiretas }\end{array}$ & $\begin{array}{c}\text { Fontes diretas } \\
\text { indiretas }\end{array}$ \\
\hline Solicitação & Tipológica & Espacial & Interativa & Material \\
\hline
\end{tabular}

Tabela 2 - Relação entre demandas e técnicas disponíveis

associação tipológica e fontes indiretas para conseguirem identificar precisamente em seu campo de trabalho o objeto com o qual irão lidar, arqueológicos têm em si uma intrínseca necessidade de trabalhar exclusivamente com a matéria dos edifícios e fontes diretas, ou seja, exclusivamente a construção, para poderem chegar à conclusóes cientificamente válidas. No meio do caminho entre esses pólos, situam-se arquitetos e conservadores, que embora possam gravitar entre formas de controle crítico relacionado a documentos sobre o objeto (fonte indireta) ou à própria matéria (fonte direta), tendem a divergirem no tipo de resultante gráfica necessária para o entendimento do bem cultural, de seus principais problemas e das formas de abordagem para a elaboração do projeto (espacial ou interativa). Uma forma de resolver essa questáo entre todos, foi, sem 
dúvida, o diálogo.

Em conclusão, em sua possível aplicação em projetos de conservação e restauração, pode-se afirmar que cada uma delas, cada tecnologia, pode ser aplicada para produzir resultados efetivos. No entanto, devido ao papel da memória no reconhecimento da arquitetura existente, tais açóes só serão válidas e eficazes desde que o usuário saiba extrair a partir de sua experiência objetiva a informação do dado coletado, em acordo com fins preservacionistas previamente estabelecidos multidisciplinarmente.

\section{REFERENCIAS BIBLIOGRÁFICAS}

BRANDI, Cesare. Teoria da Restauração. Tradução de Beatriz Mugayar Kühl. 2. ed. Cotia: Ateliê, 2005.

CARBONARA, Giovanni. “Disegnare per il restauro". In: Disegnare Idee Imagini, n. 0, Anno I, p. 85-94, 1989.

CATTANI Maurizio; FIORINI, Andrea. "Topologia: identificazione, significato e valenza nella ricerca archeologica". Archeologia e Calcolatori, n. 15, p. 317-340, 2004.

DIADRASIS INTERDISCIPLINARY RESEARCH ON ARCHAEOLOGICAL \& ARCHITECTURAL CONSERVATION. The "Romiri Project" Workshop. Athens: Diadrasis, 2011. Disponível em: <http://www.diadrasis. org/projects/romiri/>. Acesso em: 05 jun. 2011.

DOCCI, Mario; MAESTRI, Diego. Manuale di Rilevamento Architettonico e Urbano. 2 ed. amp. Roma: Laterza, 2009.

ECKSTEIN, Günther. Empfehlungen für Baudokumentationen, Stuttgart: Landesdenkmalamt Baden-Württemberg; Konrad Theiss Verlag, 1999. (Arbeitsheft, 7).

ECO, Umberto. “Entrevista: informação demais faz mal”. In: Época, São Paulo, n. 711, p. 46-49, 2 jan. 2012.

FONSECA, Maria Cecília Londres. O Patrimônio em Processo: Trajetória da Politica Federal de Preservação no Brasil. 3. ed. Rio de Janeiro: Ed. da UFRJ, 2009.

FREITAS, Pedro Murilo Gonçalves de; TIRELLO, Regina Andrade. "A síntese gráfica no processo de projeto de restauração arquitetônica”. ARQ.DOC 2010: Documentação do patrimônio arquitetônico com o uso de tecnologias digitais, 1., 2010. Salvador. Anais Eletrônicos... Salvador: LCAD; FAUFBA, 2010. v. 1, fasc. Trab_25, p. 1-12. 1 CD-ROM.

INTERNATIONAL COUNCIL ON MONUMENTS AND SITES. Carta Internacional sobre la Conservación y Restauración e Monumentos y Sítios (Carta de Venecia - 1964). ICOMOS, [S.1.], 1964.

LE GOFF, Jacques. História e Memória. Tradução de Bernardo Leitão et. al. Campinas: Ed. Unicamp, 1990.

MANACORDA, Daniela. Prima Lezione di Archeologia. 5 ed. Roma: Laterza, 2009.

SANPAOLESI, Piero. Discorso sulla Metodologia Generale del Restauro dei Monumenti. 2. ed. Firenze: EDAM, 1980.

TORSELLO, Benito Paolo. La Materia del Restauro: Tecniche e Teorie Analitiche. Venezia: Marsilio, 1988. 